Research Journal of Applied Sciences, Engineering and Technology 17(1): 13-17, 2020

DOI: $10.19026 /$ rjaset.17.6029

ISSN: 2040-7459; e-ISSN: 2040-7467

(C) 2020 Maxwell Scientific Publication Corp.

Submitted: July 17, 2019

Accepted: September 9, 2019

Published: February 15, 2020

\title{
Research Article Material Selection Techniques of Water Supply Pipe based on Analytic Hierarchy Process
}

\author{
Kamil Ali Jassim \\ Department of Mechanical Eng., College of Engineering, University of Anbar, Ramadi, Anbar, Iraq
}

\begin{abstract}
The major problem of pipes used in Water Supply System (WSSs) were analyzed and the generally, used pipe and their major features were introduced in this study. The principles that the selection on Water Supply Pipes (WSP) should follow were pointed out. Analytic Hierarchy Process (AHP) using nine scaling was applied to optimize WSPs quantitatively. The optimal WSPs were determined according to the sorting result of comprehensive evaluation index. It could provide the reference to select the reasonable WSPs for the engineers.
\end{abstract}

Keywords: Analytic Hierarchy Process (AHP), copper pipe, material selection, PP-R pipe, PVC-U pipe, water supply pipe

\section{INTRODUCTION}

Water-Supply Network has played a key role on people's life and work, which constitutes the main part of urban WSSs and becomes an integral part of urban infrastructure construction Wel and Liu (2016). Sattar and Hasan (2019) and Dawood et al. (2018) the construction of WSP network can reflect a country's economic development level in a certain extent'. Pipe is an important part of the water-supply network construction, which costs more than a third of the total cost of pipe network construction, so how to choose pipe in WSP network engineering construction holds the important status. Michael (2016) and Maleque et al. (2010) Pipe is the important restricting factor on the WSP network. At present, the outstanding problems existing in urban WSP network is as follows: corrosion is serious, the phenomenon such as pipeline dirt and 1 . aged, secondary pollution of water quality is more serious (Michael, 2016; Ogunkah and Yang, 2012). The operation energy consumption due to leakage is larger, which must be pay enough attention (Hahladakis et al., 2018). From what has been discussed above, the materials of WSP must be choose reasonably in order to achieve water pipe network reliable operation, economic and reasonable cost, convenient maintenance, no secondary pollution.

The main problems existing in the water supply pipe: Sattar and Hasan (2019) and Dawood et al. (2018) in recent years, the development trend of WSPs are diversified with the rapid development of building residential WSSs and requirements for the performance of the WSP is becoming more and more high. At present, urban water-supply network in China still has some problems, such as the leakage of pipe, blasting rate being higher and pipeline corrosion, aging and serious dirt, making water produce secondary pollution. El Chanati et al. (2016) and Liu et al. (2017) the problem cause water quality reduces, water energy consumption increase, seriously affect the economic benefits of water-supply enterprises and water security of users. In view of the city WSP network construction being not perfect and exiting some problems, in the future city pipe network transformation process, the selection of WSP should be paid more attention to reliable quality, reasonable economic indicators, in order to reduce the operating cost, save investment, ensure water-supply safely and efficiently.

\section{MATERIALS AND METHODS}

Ogunkah and Yang (2012), El Chanati et al. (2016) and Liu et al. (2017) some of the more common and analytical methods of materials selection are:

- Cost versus performance

- Weighted property indices

- Value analysis

- Failure analysis

- Benefit-cost analysis

By focusing on the economic assessment of the alternatives, Materials selection in mechanical design according to Ashby's methodology (Ashby 11) (Michael, 2016) has four basic steps which are (El Chanati et al., 2016): 
- Translation: The rapid design desires as goals and constraints

- Screening: The reduction of materials that cannot perform the job

- Ranking: The discovering of materials that perform the job better

- Supporting information: Arrange pedigrees of topranked nominees

The researchers assume that the readers are familiar with the topics facing today's production processes. Quality enhancement, regulatory compliance, Cost decreasing and so on are well recognized production competitive subjects. The difficulty arises in the formation and performance of action plans to address these topics in an atmosphere of fast and multifaceted change, partial financial and human investment and time pressure. Future automobile will offer improved performance, relaxation and function, while emitting lesser emissions, consuming less gallons of gasoline, resulting in less human harms and demanding fewer dollars to form and purchase. The only answer to these conflicting goals is to take a system vision of the product and production. Though, systems discipline is not yet standard functioning procedure.

Maleque et al. (2010) improve the MS process and select the best material for the application of the disc brake system emphasizing on the replacement of cast iron by other lightweight material. Two procedures are presented for the choice of materials, Such as the cost for each unit property and digital logic procedure. Different solutions were evaluated to best choices among cast iron, aluminum alloy, titanium alloy, ceramics and combinations. Mechanical properties such as compressive strength, friction factor, wear resistance, thermal conductivity and specific gravity besides cost, were used as crucial factors for MS. The investigation led to aluminum metal matrix composite as the best suitable material for disc brake system.

Ogunkah and Yang (2012) examined the relate disuses or variables needed to improve a systematic and effective MS method. According to the analysis of frequency data and the results of the preliminary study, they identified some of the possible factors that will influence designers' decisions in the selection of green vernacular construction materials, during the decision making of the design process.

They discussed the quantitative calculation and choice of the finest alternative for construction material, by means of the AHP method. They developed a multifactorial methodical decision support to help designers assess their significances for whether or not the MS is likely suitable for sustainability objectives. The argument of the MS process involves the assessment of social, economic, technical, sensorial and environmental significances of possible MS.

Material Selection (MS) as a competitive factor: Three forces are affecting today's enterprises; they are the three Cs: Customers, Change and Competition
(Michael, 2016). Marketing and competition deal directly with three factors Time, cost and quality. The enterprise that could catch the market with a satisfactory product or service and best price would catch a sale. Cost and quality are the most important factors in the economics of companies', van Kesteren et al. (2017).

Commonly used pipe and its features: In the water distribution system, pipe plays an important role, the factors to consider when choosing pipe have the following several aspects: the first is feed water flow and pressure of WSP, secondary water quality problems, finally, factors such as pipe installation and ease of maintenance must be given attention, according to different pipe, the different principle must be followed, El Chanati et al. (2016) and Liu et al. (2017).

Metal pipe: When metal pipes such as thin-walled stainless steel pipe and copper pipe were in use process, corrosion phenomena can also appear, which was mainly chloride and sulfide deposit. In the surface oxidation protective film inhibits corrosion, which can maintain and repair for a long time. Zhao et al. (2016) the copper pipes are influenced easily with the $\mathrm{PH}$ of water. If high acidity, corrosion phenomenon will appear. At the same time, high dissolved oxygen and demineralized water, could also result in corrosion of copper, so on these occasions, the brass try not to be used. If the chloride ions in the water content were higher, which will also cause corrosion of austenitic stainless-steel pipes, in this kind of circumstance, thinwalled stainless steel pipes is unfavorable choose. De la Fuente et al. (2016) Metal pipe connection has a variety of ways, each has advantages and disadvantages. Material, wall thickness and the use occasions must be considered comprehensively to determine pipes. If different metal tube or pipe is connected, the electrochemical corrosion of the pipeline should be pay sufficient attention.

Plastic pipe: In general, for the linear expansion coefficient, plastic pipes was more than metal pipes, which is also an important difference between plastic pipe and metal pipe. Zhao et al. (2016) and De la Fuente et al. (2016) the deformation of plastic pipe occurs in the shaft up generally. The common deformation is bending mainly in the horizontal direction and the degree of deformation is directly proportional to temperature difference. As a result, the problem must be considered in design and construction of installation, the slip joint or angle natural compensation method can be chosen. When choosing plastic pipe fittings, adhesive containing benzene class organic solvent should be avoided to choose, so as not to make water quality secondary pollution. The detection qualified tubing must be chosen according to the quality supervision and inspection authorities. 
Composite pipe: Zhao et al. (2016) and Van Kesteren et al. (2017) the welding aluminum alloy and polyethylene were adhesive by the glue to produce aluminous model multiple tube, whose characteristic was both the advantages of plastic pipe and metal pipe, namely corrosion resistance and resistance to high pressure. According to different uses of hot and cold water, aluminous model multiple tube can be divided into high density polyethylene and cross-linked polyethylene aluminous model multiple tube. Adding a layer of UPVC in the galvanized tube constitutes the plastics-steel multiple tube, which also combines the advantages of steel pipe and plastic steel pipe. The plastics-steel multiple tube commonly was used as a cold-water pipe, whose cost is higher. Steel skeleton PE pipe is a new kind of pipeline, which has the advantages of double-sided anti-corrosion pressure. PE pipe has been widely applied in municipal water-supply engineering, but its cost is higher. The plastic-coated pipe was produced with Polyethylene (PE) resin or nontoxic polypropylene and other organic matter deposited on the inner wall of the steel tube, which is characterized by high strength, water resistance, corrosion resistance, not easy fouling, long service life.

The principles to be followed when choosing WSPs material: WSP plays an important role in supplying the user with clean water. Water quality are greatly influenced by the feed water pipe. Currently, metal pipe, plastic pipe, composite pipe are three main WSP line, each has advantages and disadvantages and the accurate choice must be based on the principles of weighing the pros and cons to make, De la Fuente et al. (2016) and van Kesteren et al. (2017).

Clean sanitation: Water from the water plant generally go through a long pipeline to reach the user, during this time, chlorine that tap water contains may produce a new physical and chemical reaction with the pipe wall, water quality reaching users was affected and the inner wall of the pipe was corroded. Therefore, health performance testing qualified pipe must be chosen according to the authority supervision departments of the state, Hahladakis et al. (2018).

Safe and reliable: The WSP in the process of water distribution and supply must bear a certain amount of water pressure, meet the mechanical strength grade to prevent rupture and whose sealing must be better to prevent leakage phenomenon. At the same time, the pipe can resist the influence of vibration, water hammer and heat bilges cold shrink, all of these in pipe network design must be considered, El Chanati et al. (2016) and Liu et al. (2017).

Conducive to environmental protection: Feed water pipe can be recycled use and have no pollution to the environment, which has become an important factor when choosing pipe for technical personnel, especially country issued a series of policies to protect earth's environment. Galvanized pipe is easy to rust, which has been basically eliminated. Copper pipe with good anticorrosion performance and pressure performance, has become an important material of high-grade decoration. Most plastic pipes can be recycled, which are now also widely used, Ogunkah and Yang (2012).

Saving energy: Any pipe material in the production process and installation process must consume energy. In general, the thin-wall pipe production more efficient than thick wall pipe production. Steel-plastic compound pipe, metal pipe, plastic pipe, their production energy consumption gradually reduces. According to the construction perspective, using besmear brush twisted tooth is more energy-saving than hot melt connection, electric welding and gas welding. If a second pressure was needed in the process of water distribution, the more local head loss of the pipeline, the more energy consumption, Hahladakis et al. (2018) and Liu et al. (2017).

Saving investment: Under the condition of meeting health and safety, technical and economic analysis must be conducted from the aspects of pipe material price, construction installation cost, to choose appropriate pipes to save the cost of network construction, El Chanati et al. (2016) and Zhao et al. (2016).

Using AHP to select construction WSP: In order better to unify the qualitative analysis and quantitative analysis for decision making problem which is influenced by many factors, the AHP occurs. AHP was brought up firstly by Saaty, which was suitable for problem sorted sequence according to the advantages and disadvantages. The influence factors of building WSP are more, so it is suitable for using AHP to optimize choice. The AHP comprises several sequential steps: structuring the problem, identifying decision making factors, evaluating the importance of subfactors (indexes) and synthesizing all decision-making factor weights (Saaty, 2008). The following outline for completeness the main phases of conventional AHP, El Chanati et al. (2016) and Sattar and Hasan (2019).

\section{RESULTS AND DISCUSSION}

Setting the structure model among levels: Building WSP model mainly consists of three layers, namely the target layer, rule layer and solutions. The target layer is the building WSP. Rule layer according to the survey mainly includes health clean, safety and reliability and cost, whose importance was based on the opinions of the experts and customers to order. Fife kinds of pipes such as thin-walled copper pipes, thin-walled stainless steel pipes, PVC-U pipes, PP-R pipes, the lining of PVC galvanized pipes were choose as the research 


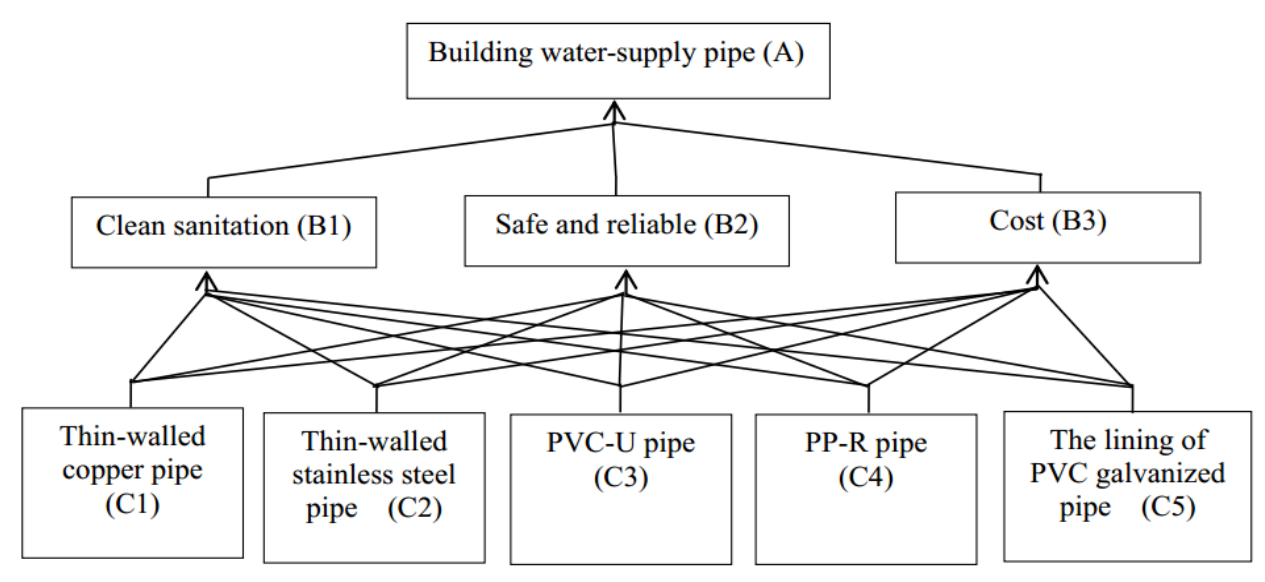

Fig. 1: Building WSP structure model figure

\begin{tabular}{llll}
\multicolumn{5}{l}{ Table 1: Building WSP decision-making target table } \\
\hline A & B1 & B2 & B3 \\
\hline B1 & 1 & 3 & 5 \\
B2 & $1 / 3$ & 1 & 3 \\
B3 & $1 / 5$ & $1 / 3$ & 1 \\
\hline
\end{tabular}

\begin{tabular}{llllll}
\multicolumn{6}{l}{ Table 2: Building WSP clean sanitation indicators table } \\
\hline B1 & C1 & C2 & C3 & C4 & C5 \\
\hline C1 & 1 & 1 & $1 / 3$ & $1 / 5$ & $1 / 3$ \\
C2 & 1 & 1 & $1 / 3$ & $1 / 5$ & $1 / 3$ \\
C3 & 3 & 3 & 1 & $1 / 3$ & 1 \\
C4 & 5 & 5 & 3 & 1 & 3 \\
C5 & 3 & 3 & 1 & $1 / 3$ & 1 \\
\hline
\end{tabular}

Table 3: Building WSP safety and reliability index table

\begin{tabular}{llllll}
\hline B1 & C1 & C2 & C3 & C4 & C5 \\
\hline C1 & 1 & 1 & 5 & 5 & 3 \\
C2 & 1 & 1 & 7 & 7 & 5 \\
C3 & $1 / 5$ & $1 / 7$ & 1 & 1 & $1 / 3$ \\
C4 & $1 / 3$ & $1 / 5$ & 3 & 3 & 1 \\
C5 & $1 / 3$ & $1 / 5$ & 3 & 3 & 1 \\
\hline
\end{tabular}

Table 4: Building WSP construction cost index table

\begin{tabular}{llllll}
\hline B1 & C1 & C2 & C3 & C4 & C5 \\
\hline C1 & 1 & 3 & 5 & 3 & 3 \\
C2 & $1 / 3$ & 1 & 3 & 3 & 1 \\
C3 & $1 / 5$ & $1 / 3$ & 1 & 1 & $1 / 3$ \\
C4 & $1 / 3$ & $1 / 3$ & 1 & 1 & $1 / 3$ \\
$\mathrm{C} 5$ & $1 / 3$ & 1 & 3 & 3 & 1 \\
\hline
\end{tabular}

object. Building WSP hierarchical model is shown in Fig. 1.

Construction of judgment matrix: According to the experience of the engineers and expert advice, nine scaling method is used to determine the element size values of judgment matrix, as shown in Table 1 to 4 .

Consistency check: The eigenvalue method is used to judge the consistency of matrix:

$$
\mathrm{CI}=\left(\lambda_{\max }-\mathrm{n}\right) /(\mathrm{n}-1)
$$

The formula of the CI shows consistency index, $\lambda_{\max }$ for the largest eigenvalue, $\mathrm{n}$ shows the number of factors, namely the order number. The mean random consistency index RI can look up to the Table 5, the consistency ratio $\mathrm{CR}$ :

$$
\mathrm{CR}=\frac{\mathrm{CI}}{\mathrm{RI}}
$$

When $\mathrm{CR}<0.1$, hierarchical sorting result consistency can be accepted.

Total sorts consistency check:

$$
\begin{aligned}
& C I_{T}=\sum_{J=1}^{5} a_{j} C I_{j} \\
& R I_{T}=\sum_{J=1}^{5} a_{j} R I_{j} \\
& C R_{T}=\frac{C I_{T}}{R I_{T}}
\end{aligned}
$$

The calculation results and analysis: AHP software v. 9.1 was used to solve the calculation, the main results as shown in Table 6 . The biggest characteristic value $\lambda_{\max }$ was obtained by the AHP software. Consistency index (CI) was obtained according to the Eq. (1), RI value can be checked by the Table 5, Consistency Ratio (CR) was calculated by the Eq. (2), total sorts consistency check according to the Eq. (5), CRT $=0.0184<0.1$, shows the total sequencing result also has the satisfactory consistency.

It can be seen from Table 6, when considering health clean, PP-R pipe is the best, when considering safety and reliability, thin-walled stainless steel pipe is the best, when considering the cost, PVC-U pipe is the best. It a word, methods 1 comprehensive weight (0.3168) is the biggest, namely the comprehensive performance of the thin-wall copper pipe is the best, which can be applied to the high standard residential WSP line installation. The second is the PP-R pipe, whose comprehensive performance is higher, plus the price and the advantages of convenient installation, which is suitable for ordinary residential decoration WSP. 
Res. J. Appl. Sci. Eng. Technol., 17(1): 13-17, 2020

Table 5: The relations between the mean random consistency index and matrix order (Van Kesteren et al., 2017)

\begin{tabular}{lllllllllllll}
\hline Matrix order & 1 & 2 & 3 & 4 & 5 & 6 & 7 & 8 & 9 & 10 & 11 & 12 \\
\hline RI & 0 & 0 & 0.52 & 0.89 & 1.12 & 1.26 & 1.36 & 1.41 & 1.46 & 1.49 & 1.52 & 1.54 \\
\hline
\end{tabular}

Table 6: Building WSP weight calculation table

\begin{tabular}{lllll}
\hline & $\mathrm{B} 1$ & $\mathrm{~B} 2$ & $\mathrm{~B} 3$ & Results total \\
\hline $\mathrm{C} 1$ & 0.6333 & 0.2605 & 0.1062 & Sorts \\
$\mathrm{C} 2$ & 0.0737 & 0.3333 & 0.4285 & 0.3168 \\
$\mathrm{C} 3$ & 0.0737 & 0.4218 & 0.2297 & 0.1809 \\
$\mathrm{C} 4$ & 0.1952 & 0.0566 & 0.0747 & 0.1790 \\
$\mathrm{C} 5$ & 0.4624 & 0.0566 & 0.0868 & 0.1771 \\
$\lambda_{\max }$ & 0.1952 & 0.1318 & 0.1804 & 0.1463 \\
$\mathrm{CI}$ & 5.0555 & 5.0955 & 5.1973 & 0.0440 \\
$\mathrm{RI}$ & 0.0124 & 0.0213 & 1.41 & 0.0312 \\
$\mathrm{CR}$ & 1.41 & 1.41 & & \\
\hline
\end{tabular}

\section{CONCLUSION}

It should master the commonly used pipe and its main features, follow the principle of the pipe selection, consider various factors and do specific analysis, to select the best pipe for exerting its maximum efficiency.

Using nine scale AHP to optimize building WSP material, it is concluded that comprehensive weight (0.3168) of thin-wall copper pipe is the biggest, which can be as a priority for building WSP. Application of AHP can break the limitations of traditional methods and more comprehensively consider various influencing factors, the evaluation results more reliable.

\section{REFERENCES}

Dawood, H.K., S.A. Mutlag, K.A. Abed and O.I. Abed, 2018. Priority-Based Decision Support System (PBDSS) by genetic algorithm as a tool for network problem. Proceeding of the 11th International Conference on Developments in eSystems Engineering (DeSE), pp: 306-311.

De la Fuente, A., O. Pons, A. Josa and A. Aguado, 2016. Multi-criteria decision making in the sustainability assessment of sewerage pipe systems. J. Clean. Prod., 112(5): 4762-4770.

El Chanati, H., M.S. El-Abbasy, F. Mosleh, A. Senouci et al., 2016. Multi-criteria decision-making models for water pipelines. J. Perform. Constr. Fac., 30(4): 401-414.

Hahladakis, J.N., C.A. Velis, R. Weber, E. Iacovidou and P. Purnell, 2018. An overview of chemical additives presents in plastics: Migration, release, fate and environmental impact during their use, disposal and recycling. J. Hazard. Mater., 344: 179-199.
Liu, G., Y. Zhang, W.J. Knibbe, C. Feng, W. Liu et al., 2017. Potential impacts of changing supply-water quality on drinking water distribution: A review. Water Res., 116: 135-148.

Maleque, M.A., S. Dyuti and M.M. Rahman, 2010. Material selection method in design of automotive brake disc. Proceeding of the World Congress on Engineering.

Michael, F.A., 2016. Materials Selection in Mechanical Design. 5th Edn., elsevier.com. 2016.

Ogunkah, I. and J. Yang, 2012. Investigating factors affecting material selection: The impacts on green vernacular building materials in the design-decision making process. Buildings, 2: 1-32.

Sattar, A.M. and H.M. Hasan, 2019. Decision making in materials selection: An integrated approach with AHP. Anbar J. Eng. Sci. AJES, 7(4): 399-407.

Van Kesteren, I.E.H., P.J. Stappers and J.C.M. de Bruijn, 2017. Materials in products selection: Tools for including user-interaction in materials selection. Int. J. Design, 1(3): 41-55.

Wel, T.Y. and D.M. Liu, 2016. Analysis of watersaving benefit and the engineering application on water-saving appliances. J. Anyang Inst. Technol., 15(2): 54-56.

Zhao, R., H. Su, X. Chen and Y. Yu, 2016. Commercially available materials selection in sustainable design: An integrated multi-attribute decision making approach. Sustainability, 8(1): 115. 